\title{
Teleoperation Using Reconstructed Graphic Model
}

\author{
Seong Youb Chung ${ }^{1}$ and Hyun Joong Yoon ${ }^{2^{*}}$ \\ ${ }^{1}$ Department of Mechanical Engineering, Korea National University of Transportation \\ ${ }^{2}$ Faculty of Mechanical and Automotive Engineering, Catholic University of Daegu \\ 재구성된 그래픽 모델을 이용한 원격제어 \\ 정성엽 ${ }^{1}$, 윤현중 ${ }^{*}$ \\ ${ }^{1}$ 국립한국교통대학교 기계공학과, ${ }^{2}$ 대구가톨릭대학교 기계자동차공학부
}

\begin{abstract}
In typical master/slave teleoperation systems, a human operator generally manipulates the master to control the slave through the visual information like camera image. However, the operator may get into trouble due to the limited visual information depending on the camera positions and the delay on the visual information because of low communication bandwidth. To cope with this inherit problem in the camera-based teleoperation system, this paper presents a teleoperation system using a reconstructed graphic model instead of the camera image. The proposed teleoperation system consists of a robot control module, a master module using a force-reflective joystick, and a graphic user interface (GUI) module. The graphic user interface module provides the operator with a 3D model reconstructed using a small set of sensing data received from the remote site. The proposed teleoperation system is evaluated through a peg-in-hole assembly task.

요 약 일반적으로 마스터/슬레이브 원격제어 시스템에서 작업자는 원격에서 슬레이브를 제어하기 위하여 카메라 영 상 같은 시각 정보를 이용하는 경우가 많은데, 많은 데이터 양으로 인하여 원격지의 영상 정보에 지연이 발생할 수 있고 카메라 위치에 따라 영상 정보가 제한되거나 불완전하여 제어가 어려운 경우가 생길 수 있다. 카메라 영상을 이 용한 원격제어 시스템의 이러한 문제점을 해결하기 위하여 본 논문에서는 영상 정보 대신에 3 차원 재구성 그래픽 모 델을 이용한 원격제어 시스템을 제안한다. 제안된 원격제어시스템은 로봇 제어 모듈, 힘반향 조이스틱을 이용한 마스 터 모듈, 그래픽유저인터페이스모듈로 이루어져 있는데, 여기서 그래픽유저인터페이스모듈은 원격지에서 전달된 적은 양의 센싱 데이터를 이용하여 3차원으로 재구성된 그래픽 모델을 작업자에게 제공해 준다. 제안된 원격제어 시스템은 펙인홀(peg-in-hole) 조립 작업을 이용하여 그 효과가 검증되었다.
\end{abstract}

Key Words : Teleoperation, Virtual Reality, Reconstructed Graphic Model, Assembly

\section{Introduction}

Teleoperation systems such as a master/slave system enable human operators to perform various tasks even in hazardous environments such as space, underwater, or an atomic power plant. In the teleoperaion systems, an operator should control the slave with the limited information of vision and touch. The vision and touch are the most important information to perform tasks successfully, and it is obvious that those losses deteriorate

This research was supported by a grant from the Academic Research Program of Korea National University of Transportation in 2012, and Basic Science Research Program through the National Research Foundation of Korea funded by the Ministry of Education, Science and Technology (No. 2010-0004341 and No. 2010-0021157).

*Corresponding Author: Hyun Joong Yoon

Tel: +82-53-850-2721 email: yoon@cu.ac.kr

Received June 08, 2012 Revised July 10, 2012 Accepted September 6, 2012 
the efficiency of the tasks. Therefore, the sophisticated sense feedback is important for the operator to perform the tasks more successfully.

A visual information system is one of the most essential and important subsystems of the teleoperation system. However, there is a situation in which vision information is insufficient or limited due to obstructions, distance, and so on. Thus, the development of the visual information system that can provide an effective display of the remote scene is required. A human operator can interact with remote environment using three types of visual information in teleoperation systems: real view, camera image, and reconstructed graphic model. The real view has a crucial drawback of location limit. Employing camera image hinders efficient real-time teleoperation due to time delay caused by excessive amount of image data, and camera image may be limited due to the viewing angle and location of the camera. The reconstructed graphic model implies the 3D virtual graphic model reconstructed using a small set of sensing data, e.g., position sensor data, received from the remote site. The teleoperation using the reconstructed graphic model can be applied in real time since it uses sufficiently small amount of image data. It is also advantageous in simulation and off-line programming. Park et al. [3] developed a supervisory control system using computer graphics for telemanipulator. It simulates a telemanipulator and objects in the virtual environment. The operator can generate instructions interactively using the simulated display of the world, and specify a 3D path for the manipulator using a mouse. The system is capable of detecting and preventing collisions.

Another important form of sensory feedback is force reflection. An operator can feel and recognize the environments and the state of operations more exactly, and can perform tasks more successfully with the haptic information. Kim et al. [2] have developed a force reflecting teleoperation simulator for training operators as a new feature. The simulated trainer enables the operator to perform a peg-in-hole task by controlling a graphically simulated telerobot with a force-reflecting hand controller. And Elhaji et al. [1] presented a new event-based control method for teleoperation systems with force feedback, which solves the problem of delay. In addition, a new force generation method was used, where the force is actually a function of the distance to obstacles in the environment of the robot. Thompson et al. [5] developed a visual tool for teleoperative experimentation involving remote manipulation and contact tasks. Using modest hardware, it recovers in real time the pose of moving polyhedral objects, and presents a synthetic view of the scene to the operator of a teleoperated robot using any chosen viewpoint and viewing direction.

Bilateral teleoperation system using the Internet as a communication channel is an issue in the teleoperation. The teleoperation system using Internet is actively investigated because it is easier to implement relatively than some kind of private communication channels. Moreover, the Internet is already well constructed. Sano et al. [4] developed a practical force reflecting teleoperator through the Internet.

The literature review shows that many researchers attempt to apply the reconstructed graphic model, the haptic feedback, and the Internet to the teleoperation. This paper presents a teleoperation system using the reconstructed graphic model with the force reflection through the Internet.

\section{Tele-manipulation system}

Figure 1 shows the system configuration of the developed teleoperation system. A human operator works using a force reflective joystick at an operation site watching the virtual model reconstructed based on the information of a remote site, and a real 5-axes robot performs a peg-in-hole task in the remote site. The remote site is sufficiently far from the operation site for the human operator not to watch the remote site directly. The both sites are connected by Internet. The human operator can control the real robot in the remote site to perform the peg-in-hole task using the force reflective joystick. The human operator feels reaction force through the force reflective joystick when the robot contacts with an obstacle during performing the peg-in-hole task. The reaction force exerted on the human operator can be helpful to successively perform the peg-in-hole task in the remote site.

The developed teleoperation system is composed of three modules, i.e., a robot control module, a graphic user 


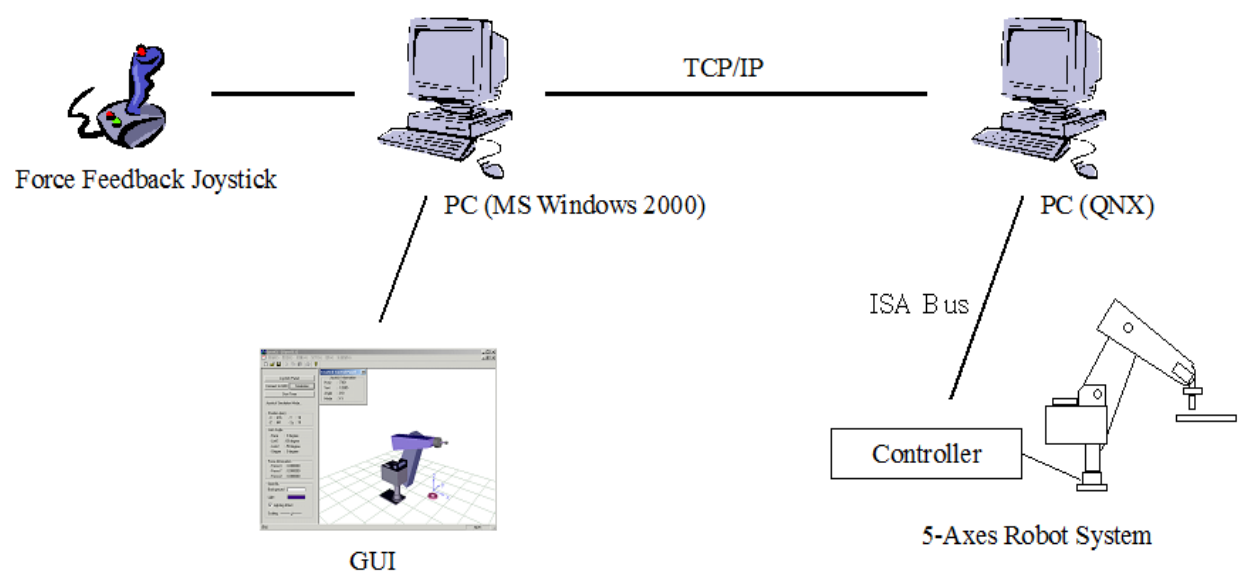

[Fig. 1] System configuration of a teleoperation system.

interface (GUI) module, and a master module using a 2-degrees-of-freedom force reflective joystick. A human operator gives the velocity commands of an end-effector of the robot using the 2-degrees-of-freedom joystick. The velocity commands includes information of three coordinates of position and an orientation. The GUI module reconstructs virtual robot model using the position sensor data received from the real robot in remote site. The virtual model can be reconstructed in real-time because it uses sufficiently small amount of information received from the remote site. The robot control module consists of a robot controller and a 5-degrees-of-freedom manipulator with position and force/torque sensor. The motion of the 5-degrees-of-freedom manipulator is determined by the velocity command transmitted from the master module. On the other hand, the position and force/torque data are sent to the master module for the reconstruction of the virtual module and reaction force of the joystick. Figure 2 shows the schematic diagram of the data flow.

\subsection{Robot control module}

The robot control module receives commands from the master module, controls the manipulator, and sends sensor information to the GUI module and the master module. It is composed of a robot controller and a 5-degrees-of-freedom manipulator with position and force/torque sensors. Its operating system is QNX which is a real time OS and provides an easy programming environment for control and communication. As shown in Fig. 2, communication and control of the robot control module are assigned to two processes, respectively. The first process only checks the message from the master module and immediately receives the command data. Then it informs the change of commands to the second process. It does not affect the control loop of the second process, since it takes very short time to check the message. The second process conducts robot control, and data acquisition and transmission. The IPC (Inter Process Communication) method is used for sharing information between the processes and the TCP (Transmission Control Protocol) method is used for communication between the robot control module and the master module.

A command from the master module consists of control mode and velocity of the end-effector. The control modes are defined as start, stop, fast, and slow. The start mode is to synchronize the robot control module and the master module, and the stop mode is to terminate the assembly process. The fast and slow modes are used for the movement of the real robot in the free-space and in assembly process, respectively.

The velocity of the end-effector has four degrees-of-freedom, that is, three translations and one rotation. These are converted to joint angular velocities by multiplication of inverse Jacobian. The robot control module performs the same command until new one is received from the master module. It sends sensor data when it receives a message from the master module. 


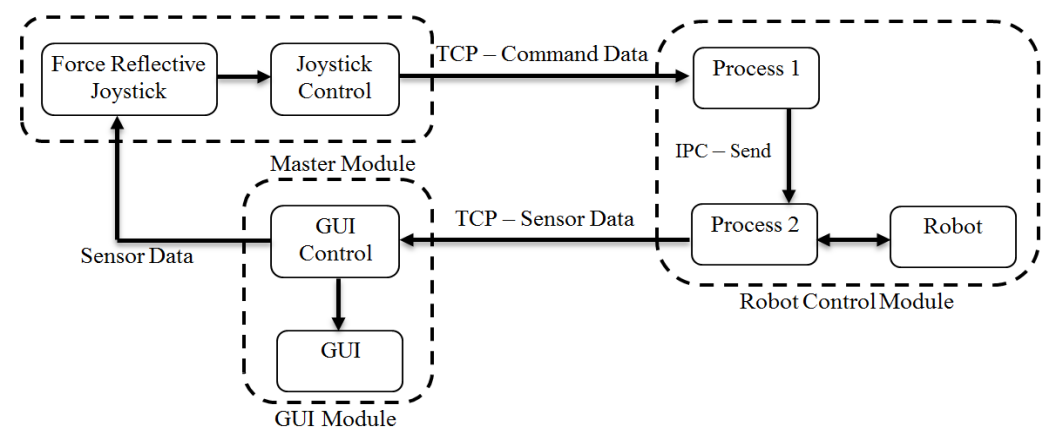

[Fig. 2] Schematic diagram of data flow

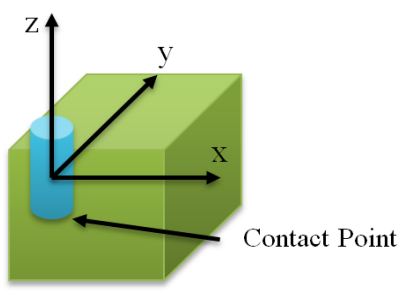

[Fig. 3] A contact on $x-z$ plane

The velocity command from the master module can damage assembly parts when contact is generated. Figure 3 shows this situation. The operator may generate the positive y-directional motion but this motion increases the contact force and may be harmful to the parts. To avoid wrong motion command, the robot control module filters the velocity commands using direction of sensed force signals. Therefore, motions to decrease the contact force can be applied to the manipulator.

\subsection{Graphic user interface (GUI) module}

The host PC in the operation site controls the force reflective joystick, communicates with the robot controller in the remote site, and reconstructs the virtual robot model using OpenGL. The GUI module provides a teleoperation mode and a simulation mode. The teleoperation mode uses both of the joystick control and TCP communication module, whereas the simulation mode uses only the joystick control module. Figure 4 shows the architecture of the teleoperation algorithm in the operation site.

If the teleoperation mode is selected, it initiates the force reflective joystick and the TCP communication with the remote site, and then the robot is set to an initial point. The virtual robot model in the GUI is reconstructed using the joint angle data received from the robot control module. When the end-effector of the manipulator contacts with an obstacle in the remote site, the force and torque data is transmitted to the joystick control module to generate reaction force.

On the other hand, when the simulation mode is selected, it initiates the force reflective joystick, and the virtual robot model runs according to the velocity command of the end-effector inputted through the joystick. A collision detection algorithm is included in the simulation mode to provide reaction force when a contact occurs during the peg-in-hole task in virtual environment. Figure 5 shows the constructed GUI module for the teleoperation system.

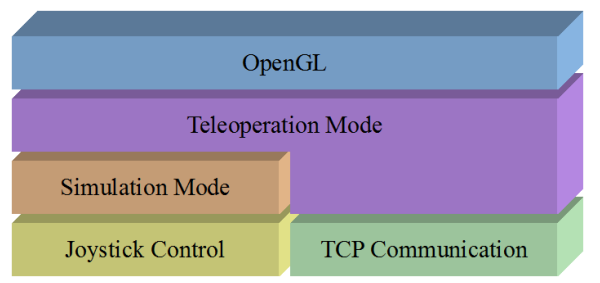

[Fig. 4] Teleoperation system architecture at operation site

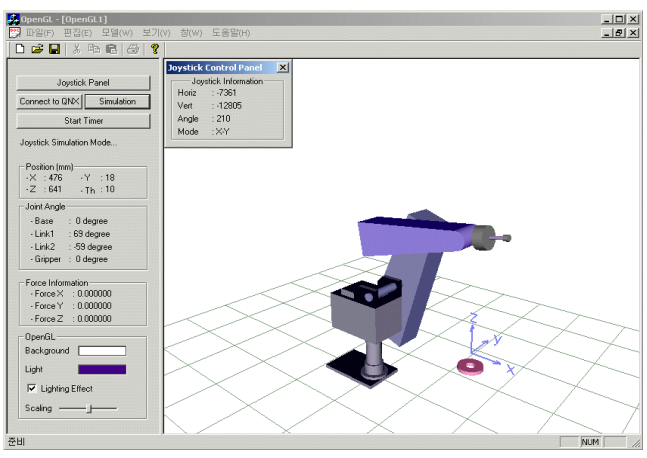

[Fig. 5] Graphic user interface 

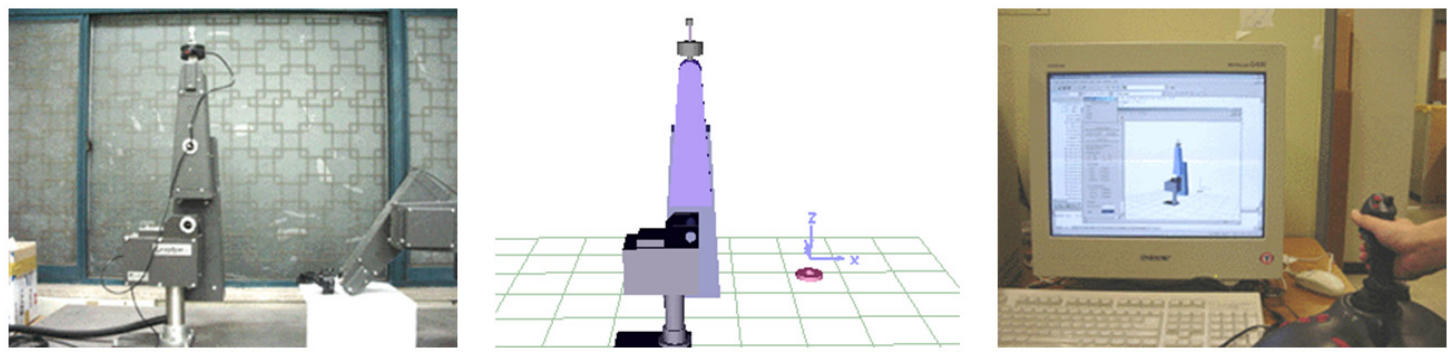

(a) Initial position to wait message from the master module
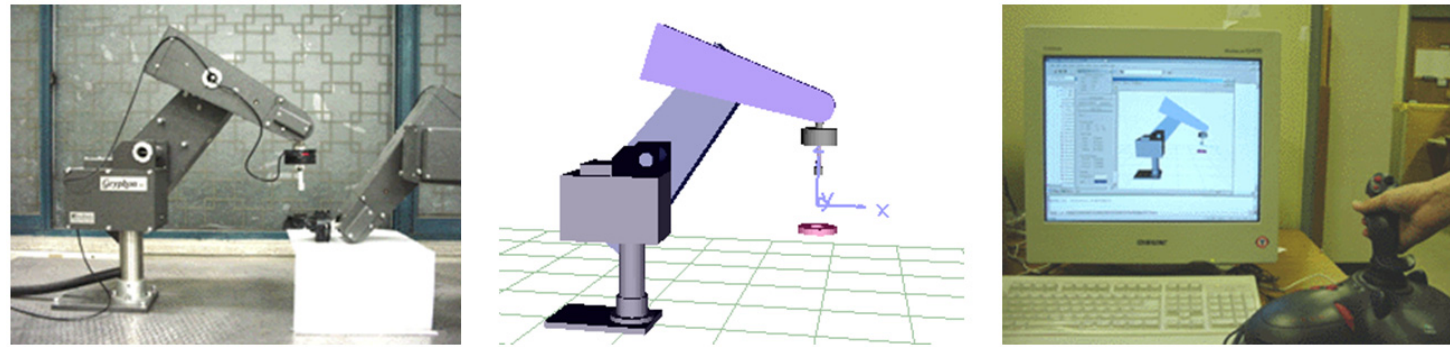

(b) Pre-assembly position
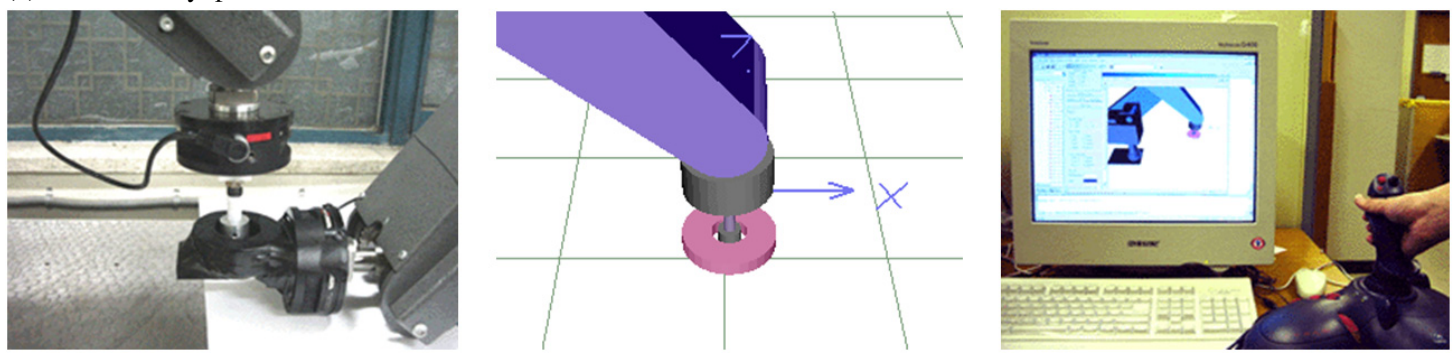

(c) End of peg-in-hole assembly

[Fig. 6] Snapshots of teleoperation using reconstructed graphic model

\section{Experiment}

A peg-in-hole assembly is selected for evaluation of the proposed teleoperation system. The robot control module initializes the manipulator and waits the message from the master module. It moves the manipulator to the pre-assembly position with quick motion. And then, the teleoperation of peg-in-hole assembly starts. A user handles the force-feedback joystick with the 3D reconstructed model and controls view of the model by zooming, rotating, and panning screen using a mouse. The motion direction and velocity of the robot are determined by the direction and angle of the joystick, respectively. After moving to the assembly workspace automatically, the robot is connected with the tele-manipulation system. The maximum speed of the end-effector of the robot for the assembly task is predetermined as $10 \mathrm{~mm} / \mathrm{sec}$. During the peg-in-hole assembly controlled by the joystick, a collision is detected through the force/torque sensor located at the wrist of the robot. If any collision is detected from the force/torque sensor, the information is transmitted to the tele-manipulation system. The user can notice the collision by the vibration of the joystick. Thus, the user operates the peg-in-hole assembly task more effectively thorough the collision information. Figure 6 shows snapshots of the teleoperation. First column of the figure is operation of the real robot, the second is that of the reconstructed graphic model, and the third is that of the master module. Experiments show that operators successively perform the peg-in-hole task after several trainings in simulation mode. 


\section{Conclusion}

This paper proposes a teleoperation system using the reconstructed graphic model, which is advantageous in real time application because it uses sufficiently small amount of information from the remote site. The experiment with the pen-in-hole assembly shows that the developed teleoperation system is efficient in on-line application. Because the developed teleoperation system uses only the sensor data, the reconstruction rate of the virtual robot model in the GUI is sufficiently fast for the human operator to perform the peg-in-hole assembly task. And the reaction force through the force reflective joystick provides the human operator a guideline for successful pen-in-hole task in the remote site.

The developed teleoperation system uses a vibration mode of the force reflective joystick to indicate that the end-effector contacts with an obstacle during performing the peg-in-hole task. However, the vibration mode may not be effective for the more complicated task. Therefore, it is needed to develop a more effective force reflection algorithm for the future work.

\section{References}

[1] I. Elhaji, N. Xi, and Y. H. Liu, "Real-Time Control of Internet Based Teleoperation with Force Reflection", Proc. of IEEE Conference on Robotics \& Automation, San Francisco, CA, pp. 3284-3289, April, 2000.

[2] W. S. Kim and A. K. Bejczy, "Graphics Displays for Operator Aid in Telemanipulation", Proc. of IEEE Conference on Systems, Man, and Cybernetics, pp. 1059 - 1067, vol.2, 1991.

[3] J. H. Park and T. B. Sheridan, "Supervisory Teleoperation Control Using Computer Graphics", Proc. of IEEE Conference on Robotics and Automation, Sacramento, California, pp. 493-498, April, 1991.

[4] A. Sano, H. Fujimoto, and T. Takai, "Network-Based Force-Reflection Teleoperation", Proc. of IEEE Conference on Robotics \& Automation, San Francisco, CA, pp. 3126-3131, April, 2000.

[5] R. L. Thompson, I. D. Reid, L. A. Munoz, and D. W. Murray, "Providing Synthetic Views for Teleoperation Using Visual Pose Tracking in Multiple Cameras", IEEE Transactions on Systems, Man, and Cybernetics,

Part A, vol. 31, no. 1, pp. 43-54, Jan. 2001.

Seong Youb Chung

[Regular member]

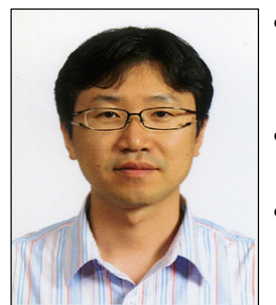

- Feb. 1994 : Yonsei University, Department of Mechanical Engineering, B.S.

- Feb. 1996 : KAIST, Department of Mechanical Engineering, M.S.

- Feb. 2005 : KAIST, Department of Mechanical Engineering, Ph.D.

- Apr. 2005 Mar. 2007 : Samsung Heavy Industries Co. Ltd., Senior Researcher

- Apr. $2007 \sim$ Current : Korea National University of Transportation, Department of Mechanical Engineering, Assistant Professor

$<$ Research Interests $>$

Affective Computing, Machine Vision, Robotics

\section{Hyun Joong Yoon}

[Regular member]

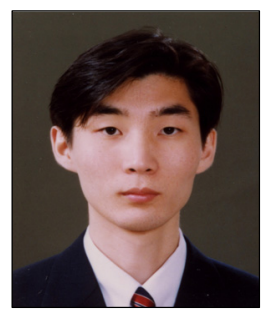

- Feb. 1997 : Yonsei University, Department of Mechanical Engineering, B.S.

- Feb. 1999 : KAIST, Department of Mechanical Engineering, M.S.

- Feb. 2004 : KAIST, Department of Mechanical Engineering, Ph.D.

- Apr. $2004 \sim$ Mar. 2005 : National Research Council Canada, Researcher

- May $2005 \sim$ Aug. 2008 : Samsung Electronics Co. Ltd., Senior Researcher

- Sep. $2008 \sim$ current : Catholic University of Daegu, Faculty of Mechanical and Automotive Engineering, Assistant Professor

$<$ Research Interests $>$

Affective Human-Robot Interaction, Medical Robot 